\title{
Relato e análise de uma sequência didática sobre forças de atrito com uso de kits de robótica educacional no primeiro ano do ensino médio
}

\section{Report and analysis of a teaching and learning sequence about friction forces using Educational Robotics at first years' classes in a high-school}

\author{
Toni Fernando Mendes dos Santos ${ }^{1}$, Paulo José Sena dos Santos ${ }^{2}$ \\ ${ }^{1}$ Mestrando PPGECT UFSC - sgttoni@gmail.com \\ ${ }^{2}$ Professor Associado do Departamento de Física UFSC - paulo.sena@ufsc.br
}

\begin{abstract}
Resumo: No primeiro ano do ensino médio são ensinados em Física os conceitos básicos sobre força e movimento. Neste momento, o atrito, apesar de sua importância no cotidiano, é discutido de maneira muito rápida. Além disso, algumas investigações mostram que a abordagem tradicional utilizada nas discussões não permite aos estudantes superarem as suas concepções espontâneas sobre esta força. Neste contexto, o presente trabalho apresenta uma abordagem com a utilização de elementos de robótica educacional - muito utilizada para investigações em cinemática - para o ensino desta força. Depois de uma análise qualitativa dos dados obtidos através de questões abertas, observa-se que as atividades permitiram a identificação e posterior discussão de algumas das concepções mapeadas na literatura.
\end{abstract}

Palavras-chave: Forças de atrito. Robótica educacional. Ensino de Física.

\begin{abstract}
In the first year of high school students study in physics the basic concepts about force and movement. At the moment, friction despite its importance in daily life is briefly discussed. In addition, some research shows that the traditional way of presenting friction does not allow students to overcome their misconceptions about this force. To enable students to overcome these conceptions we propose an approach with the use of educational robotics, which is much investigated for the discussion of concepts in kinematics. In this context, we conducted an investigation on the feasibility of its use for the teaching of static and kinetic friction. After a qualitative analysis of the data obtained through the application of questions opened during a teaching and learning sequence, our results showed that the activities developed allowed the identification and discussion of some alternative conceptions pointed out by different researchers.
\end{abstract}

Keywords: Friction forces. Educational Robotics. Physics teaching.

\section{Introdução}

Nas últimas décadas muitas pesquisas investigaram as concepções alternativas (ou espontâneas) em Física. Geralmente, estas ideias divergem da teoria cientificamente aceita e se aproximam de concepções que já foram abandonadas historicamente. Estas concepções não correspondem a simples erros, pois se originam da tentativa de entender um mundo composto por objetos e pelas relações sociais e culturais estabelecidas em torno deles. Para Pozo e Crespo (2009) essa é uma importante razão para a dificuldade dos estudantes em abandoná-las mesmo com o avanço dos anos na escola. Assim, um dos objetivos do Ensino de Física é criar situações que permitam o entendimento e o uso das concepções cientificamente aceitas. 
No primeiro ano do ensino médio os estudantes entram em contato com os conceitos básico sobre força e movimento. Nesse contexto, apesar de sua importância no cotidiano, o atrito é discutido brevemente e, em geral, de maneira abstrata e esquemática (BESSON et al, 2007). Alguns estudos (CALDAS e SALTIEL, 1995; CALDAS, 1999; BESSON et al, 2007; HANÇER e DURKAN, 2008; BÏLAL e EROL, 2010) mostraram que as principais concepções alternativas relacionadas a este tema são: (a) o atrito sempre afeta objetos em repouso; (b) o atrito depende da área de contato entre o objeto e a superfície; (c) atrito é uma propriedade do corpo e não causado por uma interação entre superfícies; (d) o atrito é sempre oposto a direção do movimento; (e) os atritos cinético e de rolamento são designações equivalentes da mesma força; (f) existe uma dependência entre o atrito e a velocidade relativa do movimento entre as superfícies. Os trabalhos citados também apontam que uma abordagem tradicional não auxilia os estudantes a superarem suas concepções espontâneas sobre essas forças.

Com base no exposto, neste trabalho serão apresentados um relato e uma breve análise de uma sequência didática para a discussão do atrito com o uso de kits de robótica educacional (RE). Embora o emprego da RE tenha crescido nos últimos anos, quando o assunto é o Ensino de Física, sua utilização se concentra na discussão de temas em cinemática (SPOLAÔR e BENITTI, 2017). Este panorama também se repete no Brasil (AGUIAR et al, 2017; FORNAZZA e WEBER, 2014; ROUXINOL et al, 2011; TRENTIN et al, 2015).

É importante citar que, independente dos conceitos ou disciplinas, a RE permite desenvolver competências e habilidades relacionados ao trabalho colaborativo, ao uso de tecnologias, ao pensamento computacional, entre outros. Além deste ponto, os diferentes trabalhos citados apontam um aparente aumento da motivação em sala de aula.

\section{As forças de atrito}

Desde a antiguidade a humanidade tem observado os efeitos dessa força, porém alguns registros indicam que o primeiro estudo mais sistematizado sobre o tema foi realizado por Leonardo da Vinci no século XV. Ele observou que o atrito entre duas superfícies diferentes dependia da compressão exercida pelos corpos, mas não da área de contato. Outros estudos realizados por Guillaume Amontons, em 1699, e Coulomb, em 1785, conduziram a três leis clássicas. De acordo com estas leis, o atrito: depende do valor da força de contato ou força normal $(\mathrm{N})$ entre as superfícies, é independente da área (A) de contato entre as superfícies e, no caso dinâmico, é independente da velocidade relativa entre as duas superfícies (BESSON et al, 2007).

Euler ao investigar o movimento de corpos em planos inclinados propôs um modelo para explicar o atrito de deslizamento entre sólidos que é utilizado até hoje nos diferentes níveis de ensino. Segundo este modelo as forças de atrito podem ser explicadas através das imperfeições presentes nas superfícies que produziriam ao entrar em contato "encaixes". Essas forças estariam associadas a necessidade de rompimento desses "encaixes" durante o deslizamento das superfícies dos objetos.

Através da análise da geometria da situação ele encontrou uma relação entre o coeficiente de atrito estático $\left(\mu_{s}\right)$, característico das superfícies em contato, com o ângulo de inclinação $(\theta)$ do plano

$$
\mu_{s}=\tan \theta
$$

Ele também propôs que a força de atrito $\left(F_{a t}\right)$ é diretamente proporcional a força de compressão (ou normal - $N$ ) exercida pelo objeto sobre a superfície 


$$
F_{a t}=\mu_{s} \cdot N
$$

Outra característica da força de atrito é a mudança em sua intensidade após o objeto entrar em movimento. Quando você exerce uma força sobre um objeto para movê-lo, não é com qualquer força que se é bem-sucedido. Neste caso, a força de atrito, denominada atrito estático, aumenta de 0 até um valor máximo, denominado atrito estático máximo $-F_{\text {emax }}$, que pode ser determinado através da relação (2). Quando o objeto começa a se mover, a intensidade do atrito diminui até um valor praticamente constante denominado atrito cinético $\left(F_{k}\right)$, que pode ter seu valor calculado através da relação

$$
F_{k}=\mu_{k} \cdot N
$$

onde o coeficiente de atrito cinético $\left(\mu_{k}\right)$ é menor que o estático $\left(\mu_{s}\right)$. Os estudantes também demonstram dificuldade no entendimento deste comportamento.

Mossmann et al (2002), discutiram a determinação dos coeficientes de atrito estático e cinético entre blocos de madeira e diferentes superfícies (carpete, lixa, borracha, entre outros) através de um sistema de coleta de dados automatizada conectada a um sensor de força. Eles observaram que o coeficiente de atrito cinético oscila em torno de um valor médio e se torna constante após o objeto adquirir um movimento retilíneo uniforme. Porém, num modelo simplificado pode-se considerar o coeficiente de atrito cinético constante.

\section{As atividades realizadas}

$\mathrm{Na}$ elaboração das atividades para o ensino sobre as forças de atrito foram feitas algumas escolhas: (i) apesar das diversas concepções espontâneas mapeadas na literatura, foram trabalhadas as apresentadas nos itens b, c e f da introdução; (ii) para a análise do fenômeno envolvendo os atritos estático e cinético foi utilizado o modelo de Euler; (iii) no início da sequência didática as leis de Newton foram discutidas de maneira mais próxima a tradicional - essa abordagem foi escolhida para que os estudantes tivessem mais tempo para trabalhar nas atividades propostas; (iv) durante as atividades sobre o atrito foram utilizadas questões abertas, pois elas requerem reflexões para a elaboração das respostas e a identificação de concepções espontâneas pelos estudantes e pelos professores; (v) o professor da turma participou do planejamento das atividades - ele contribuiu com sugestões importantes a respeito da adequação da carga de trabalho envolvida, linguagem utilizada no material, entre outros, mas a condução das aulas foi realizada pelos pesquisadores; (vi) durante as atividades que envolviam a discussão das forças de atrito, os grupos de estudantes discutiam e respondiam a questões abertas para a promoção da reflexão dos resultados obtidos.

Nas aulas foram utilizados os kits desenvolvidos e fabricados pela ATTO Educacional e o ambiente de programação Ardublock (um ambiente de programação gráfico para o Arduino).

As primeiras atividades realizadas tinham como objetivo apresentar o material a ser utilizado, assim como o ambiente de programação. As tarefas basicamente consistiam em acender e apagar leds e criar dispositivos interativos para a discussão do funcionamento de potenciômetros e motores. Essas atividades utilizaram roteiros fechados, similares aos utilizados em laboratórios tradicionais, e não serão discutidas nesse trabalho.

Depois foi realizada uma primeira discussão sobre o atrito para que os estudantes tomassem conhecimento de suas concepções sobre o tema. Esta discussão foi 
necessária para o desenvolvimento da próxima atividade, onde os estudantes realizaram a determinação do coeficiente de atrito estático. Nessa prática, cada grupo utilizou um bloco de madeira com quatro faces distintas. Em duas faces com áreas diferentes foram coladas lixas, nas outras duas foram colados papel e eva. Os estudantes colocaram o bloco em um plano inclinado ligado a um servo motor controlado por um potenciômetro (figura 1). Então eles visualizaram na tela o ângulo em que bloco começava a deslizar. Este procedimento foi repetido diversas vezes para cada face do bloco.
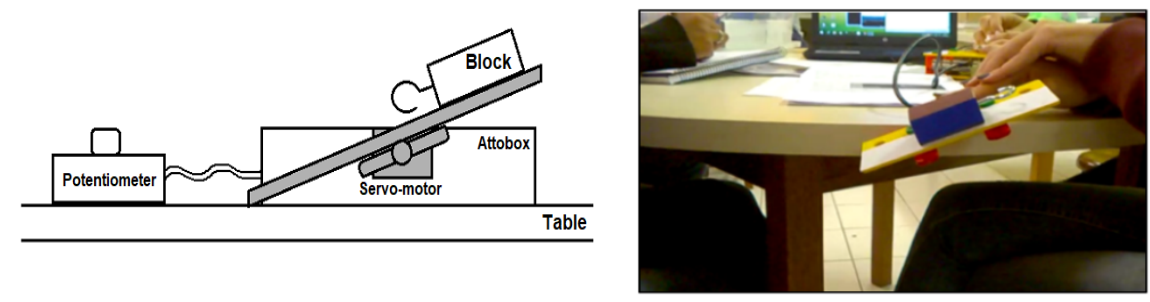

Figura 1: Experimento para a determinação do atrito estático. Fonte: elaborada pelos autores.

Depois dessas atividades os grupos tiveram que realizar uma pesquisa para responder a duas questões para um primeiro contato com o modelo de Euler: (a) por que podemos utilizar um plano inclinado para determinar o valor do coeficiente de atrito estático? (b) Qual é a relação entre o ângulo em que o bloco começa a deslizar e o valor deste coeficiente?

Nas últimas aulas, os estudantes determinaram o coeficiente de atrito cinético. Para esta prática eles utilizaram um potenciômetro para controlar um motor dc. A tarefa consistia em utilizar o motor para puxar o bloco, utilizado na atividade anterior, sobre uma superfície revestida por uma folha de papel. A força de tensão exercida sobre o bloco (antes e depois dele começar o seu movimento) eram medidas através de um dinamômetro, como pode ser visto no esquema da figura 2 .

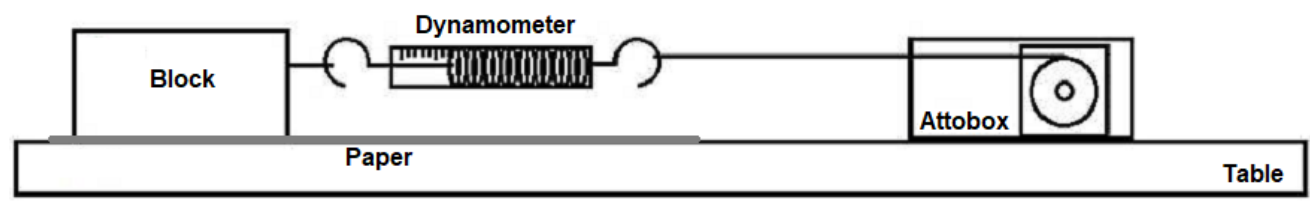

Figura 2: Esquema do experimento realizado para determinação do coeficiente de atrito cinético. Fonte: elaborada pelos autores.

Um resumo das atividades realizadas pelos estudantes e sua duração pode ser visto na tabela 1 (cada aula durou 45 minutos).

Tabela 1: Resumo das atividades

\begin{tabular}{|c|c|c|}
\hline Aulas 1,2 e 3 & $135 \mathrm{~min}$ & $\begin{array}{l}\text { Atividades com LEDs, motores e sensores (para que os } \\
\text { estudantes tivessem um primeiro contato com o material). }\end{array}$ \\
\hline Aula 4 & $45 \min$ & Discussões sobre o atrito. \\
\hline Aulas 5,6 e 7 & $135 \mathrm{~min}$ & $\begin{array}{l}\text { Atividades para determinação do coeficiente de atrito } \\
\text { estático. }\end{array}$ \\
\hline Aulas 8 e 9 & $90 \mathrm{~min}$ & $\begin{array}{c}\text { Atividades para a determinação do coeficiente de atrito } \\
\text { dinâmico. }\end{array}$ \\
\hline $\begin{array}{l}\text { Aulas } 10,11 \mathrm{e} \\
12\end{array}$ & $135 \mathrm{~min}$ & $\begin{array}{c}\text { Discussão dos resultados. Após o final das atividades, os } \\
\text { grupos entregaram os relatórios dos experimentos } \\
\text { realizados e os diários de campo. }\end{array}$ \\
\hline
\end{tabular}




\section{Metodologia}

A sequência proposta foi aplicada em uma escola pública federal localizada em Florianópolis. As atividades foram realizadas em duas turmas do primeiro ano do ensino médio, com aproximadamente 25 estudantes cada. Também foram disponibilizados horários no contra turno para que os estudantes pudessem esclarecer dúvidas e completarem as tarefas propostas em sala.

Cinquenta estudantes, com idades entre 15 e 16 anos, participaram das atividades. Deve-se ressaltar que os alunos participantes não tiveram nenhum contato com a robótica ou os kits utilizados antes do desenvolvimento do trabalho. Também é importante comentar que essa foi a primeira vez que eles estudaram a física como uma disciplina, entretanto, alguns estudantes discutiram alguns conceitos - como aceleração - de maneira mais simplificada em anos anteriores na disciplina de ciências. Dessa forma, por hipótese, considerou-se que suas concepções sobre o atrito se aproximam das concepções alternativas identificadas na literatura.

Durante as atividades para a discussão das forças de atrito os estudantes foram divididos em grupos compostos por aproximadamente cinco integrantes cada. Os grupos receberam questões abertas a serem respondidas antes, durante e após as atividades. As perguntas formuladas tinham como objetivos: a promoção de reflexões sobre a física envolvida nas situações propostas, a discussão da validade e dos limites dos modelos utilizados e a discussão das estratégias necessárias para a resolução das situações.

Após as aulas, os pesquisadores analisaram as respostas dos estudantes para identificar suas concepções e interpretações dos resultados dos experimentos. Posteriormente, compararam-se os resultados obtidos com os apontados pela literatura. Finalmente, foram analisadas as opiniões sobre as aulas e o uso dos kits de robótica.

\section{Análise das respostas para as questões abertas}

Durante as aulas introdutórias os estudantes fizeram muitas perguntas que possibilitaram o estabelecimento de relações entre os diferentes componentes dos kits e os dispositivos presentes no dia-a-dia. Nas atividades sobre o atrito, os grupos, de maneira geral, foram participativos. Nesta seção serão apresentados os principais elementos das respostas dos estudantes as questões abertas das atividades.

\subsection{Atividade para a determinação do atrito estático}

Questão 1: Vocês já pensaram em viver em um mundo sem a existência das forças de atrito? Como esse mundo deveria ser?

Esta questão teve como objetivo identificar as principais opiniões sobre o papel atrito nos fenômenos cotidianos. Três tipos de respostas eram esperados: (i) que as pessoas e os objetos permaneceriam em movimento para sempre; (ii) que não poderia existir movimento, uma vez que sem atrito as pessoas não conseguiriam andar; (iii) não seria possível parar os objetos em movimento devido a ausência de resistência.

A análise das respostas mostrou que três grupos apresentaram a resposta (i), enquanto seis grupos apresentaram a resposta (ii). Um grupo apresentou parcialmente a resposta (iii), pois argumentou que embora não fosse possível iniciar um movimento, objetos que já estivessem em movimento permaneceriam em movimento retilíneo uniforme (MRU). 
Questão 2: Sem a presença de forças de atrito poderia existir movimento? Argumentem a respeito.

Esta questão complementava a primeira. Eram esperadas respostas do tipo: (i) não, pois sem atrito não se pode andar ou empurrar objetos; (ii) sim, pois o atrito apenas atrapalha os movimentos.

Os argumentos apresentados a favor da existência dos movimentos apontaram para a possibilidade de movimentos permanentes em locais onde o atrito não é observado, como pode ser exemplificado no extrato: "Poderia, apenas não poderíamos iniciar um movimento. (...) O movimento do que já estava em movimento seria infinito, retilíneo e uniforme" (Grupo 6).

Os argumentos contrários foram baseados não existência de movimento devido ao fato da impossibilidade de empurrar objetos, como ilustra o exemplo: "Não existiria movimento algum. Não iria ter porque não daria para empurrar a superficie”" (Grupo 4).

Questão 3: De acordo com os resultados de sua experiência, a força de atrito modificase dependendo dos tipos de superfície que interagem entre si? Descreva o que foi observado.

O objetivo da questão era promover uma reflexão sobre a dependência do atrito com as superfícies em contato. A concepção espontânea comumente associada é a de que o coeficiente de atrito é uma propriedade do objeto. Assim, era esperado que os estudantes observassem que um mesmo objeto pode ter diferentes coeficientes de atrito, uma vez que ele resulta da interação entre duas superfícies em contato. Além desse aspecto, era esperado que os estudantes estabelecessem relações qualitativas entre as diferentes inclinações do plano e a dificuldade de colocar um objeto em movimento, visto que o modelo matemático ainda não havia sido apresentado aos estudantes. Aspectos associados a essa relação qualitativa foram encontrados em todas as respostas, como ilustra o exemplo: "(...) devido a dependência com as superficies em contato o objeto começará a cair com diferentes ângulos. Quanto maior o atrito, maior será o valor do ângulo" (Grupo 1).

Entretanto, após as atividades pode-se perceber algumas respostas que ainda associavam o atrito com alguma propriedade do objeto, como por exemplo: “(...) observamos que objetos mais lisos possuem menos atrito comparados a superficies mais ásperas" (Grupo 2).

Questão 4: Você já deve ter percebido que quanto mais pesado é um objeto, mais difícil é arrastá-lo por uma superfície. Será que o peso ou a massa do objeto tem alguma coisa a ver com a força atrito? Explique.

O objetivo da questão era provocar uma reflexão sobre a relação entre o atrito e o peso ou a massa do corpo. De acordo com Besson et al (2007) é comum relacionar o atrito com essas duas grandezas. É importante os estudantes perceberem que o atrito está relacionado à força normal, que em alguns casos é relacionada ao peso do corpo.

Foram encontrados dois tipos de respostas para essa questão. No primeiro os grupos consideraram que um aumento da massa do objeto é capaz de provocar uma mudança na compressão da superfície. Deste modo, quando a massa aumenta, aumenta a força normal sobre a superfície e, consequentemente, o valor do atrito estático irá aumentar, como ilustrado no exemplo: "Sim, pois quanto mais pesado o objeto, mais ele vai comprimir a superficie, interferindo na força de atrito” (Grupo 4).

No segundo tipo, os grupos interpretaram corretamente a situação. Eles argumentaram que a força de compressão pode ser independente do peso, logo em 
alguns casos eles não estão relacionados, como mostra o exemplo: "Nem sempre o peso tem a ver, tudo depende da força normal e quanto o objeto comprime a superfície " (Grupo 6).

Questão 5: A massa do objeto altera o coeficiente de atrito entre o objeto e a superfície em que ele está apoiado?

Era esperado que os grupos pensassem sobre a diferença entre a força de atrito e o coeficiente de atrito. Este é um ponto importante, pois a força pode variar em alguns casos devido ao aumento da massa, enquanto o coeficiente de atrito pode ser considerado constante. Sete grupos não perceberam essa diferença. Por exemplo, um grupo respondeu: "Sim. Porque quanto maior a massa do objeto, mais força de atrito é presente no objeto" (Grupo 2).

Três grupos responderam que o coeficiente de atrito é uma propriedade que se origina em uma interação. Por exemplo, o grupo 8 afirmou que: "Não. O coeficiente de atrito é dado pelas superfícies em contato, não pela massa do objeto”.

\subsection{Atividade para determinação do atrito cinético}

Questão 1: Imagine que você tem que empurrar uma grande caixa em formato retangular por uma sala. Supondo que todos os lados da caixa são constituídos do mesmo material, será que o fato de manter a caixa em pé ou deitada fará diferença na hora de empurrá-la? Por que?

O objetivo dessa questão foi observar se os estudantes respondiam com base na concepção de que existe uma relação entre o atrito e a área de contato entre as superfícies.

Quatro grupos relacionaram o aumento da área de contato com o aumento do atrito, como pode ser ilustrado pelo exemplo: "Sim, a superficie em contato com o solo pode ser maior ou menor, quanto mais espaço em contato mais dificil o deslocamento, quanto menos contato mais fácil" (Grupo 10).

Curiosamente um grupo citou que seria mais difícil empurrar a caixa se a área em contato fosse menor. Eles argumentaram que quando o bloco estivesse apoiado na maior área o peso estaria mais distribuído, assim empurrar a caixa seria mais fácil.

Cinco respostas apontaram que não faria diferença, pois o que importa são os materiais das superfícies e a força de compressão (normal) exercida pela caixa sobre o chão.

Questão 2: O que vocês observaram na atividade, alterar o tamanho da área em contato modificou o valor da força de atrito?

Era esperado que após a atividade prática os estudantes percebessem que o atrito independe da área de contato entre as superfícies. Contudo, algumas flutuações nos resultados experimentais (que são comuns neste tipo de atividade) levaram os estudantes a concluir que havia algum tipo de relação entre essas grandezas.

Neste momento decidiu-se discutir em mais detalhes esse resultado, os problemas que podem ter ocorrido com o experimento, e as flutuações que podem ocorrer devido a natureza do atrito (MOSSMANN et al, 2002).

Após análise do ocorrido, concluiu-se que, para reduzir esses efeitos, é necessário fazer melhorias em alguns componentes dos kits e no design da atividade. Como relatado por Mossmann et al (2007), estas flutuações são comuns no início do movimento e desaparecem quando o objeto adquire o movimento uniforme. Assim, um aumento na distância percorrida pelo bloco deve reduzir o efeito das flutuações. 
Questão 3: Houve alguma alteração na marcação do dinamômetro antes e depois de iniciar o movimento? Descrevam o que aconteceu.

Todos os grupos relataram uma redução no valor indicado pelo dinamômetro após o início do movimento. Eles conseguiram perceber as diferenças entre os valores dos atritos estático máximo e cinético.

Questão 4: Por que pneus de F1 são tão largos comparados com os pneus dos outros carros de rua?

Para responder essa questão os grupos deveriam realizar uma pesquisa e sintetizar alguns aspectos discutidos em sala. Alguns grupos concluíram que o principal fator é o desgaste que ocorre durante uma corrida. Eles explicaram que uma maior área de contato reduz a pressão sobre o solo, o que provoca menor aquecimento e consequentemente um menor desgaste.

Mas, alguns grupos ainda responderam com base em suas concepções relacionando ao aumento do atrito. É importante observar que os pneus destes carros são feitos de um polímero que apresenta uma pequena relação entre a área de contato e o atrito, mas esse não é o fator principal. Esses detalhes foram discutidos com os estudantes e se destaca a possibilidade de argumentação sobre as limitações dos modelos trabalhados na sala de aula.

\subsection{Considerações dos estudantes sobre as atividades}

Ao final de cada atividade, os estudantes receberam um questionário para discutir tópicos como: quais conceitos físicos foram abordados, quais dificuldades foram encontradas, avaliação do trabalho em grupo e da própria atividade em si. Abaixo, traçamos um panorama dos resultados obtidos, uma vez que as respostas puderam ser agrupadas.

Em relação ao primeiro tópico, os estudantes conseguiram, de modo geral, enumerar quais conceitos físicos foram trabalhados, entretanto não souberam especificar de que forma eles apareciam no desenvolvimento das atividades. Como exemplo, sabiam que conceitos como força normal, peso, coeficiente de atrito estavam sendo trabalhados, mas não conseguiam expressar com clareza de que forma isso ia sendo discutido no decorrer do processo. Questões desse tipo exigem uma interpretação mais refinada, dessa forma deverão ser mais bem exploradas pelo professor em oportunidades futuras, principalmente no fechamento das atividades.

Quanto às dificuldades encontradas, as principais foram: responder questões abertas e a linguagem de programação. Embora relatadas como dificuldade, as questões abertas foram bastante elogiadas pelos grupos, pois segundo eles, propiciou discussões interessantes para além da sala de aula. No tocante à programação, apesar da linguagem ser amigável, o tempo para realização das atividades era um limitante, o que pode ter prejudicado maior apropriação por parte de alguns alunos. Outras dificuldades como manipulação dos equipamentos (uso do dinamômetro), falha de comunicação entre a placa e o computador foram mencionadas em menor grau.

Ao responderem sobre o trabalho em grupo e como as discussões contribuíram para as atividades, todos apontaram aspectos positivos, uma vez que na opinião dos participantes esse tipo de atividade favorece a exploração de diferentes pontos de vista e a superação de dificuldades. Assim, os estudantes perceberam o trabalho de grupo como uma dinâmica capaz de promover a argumentação entre pares, a socialização de dúvidas 
e incertezas, e o diálogo para o entendimento de conceitos. Esses pontos aparecem em outros trabalhos (MITNIK et al, 2009; TRENTIN et al, 2015; WILLIAMS et al, 2007).

Por fim, ao avaliarem as atividades, as respostas foram bastante satisfatórias. Os estudantes demonstraram ter gostado das práticas e das discussões que delas se desenrolaram. Em geral, pesquisadores da área apontam o fato do uso da RE ser prazeroso, especialmente devido às interações que ocorrem nesse tipo de abordagem, algo menos provável de ocorrer nas aulas tradicionais, além do próprio contato com a tecnologia. Tal fato permite avaliar que a RE possui grande potencial para confecção de novas atividades e ainda há muito a ser explorado.

\section{Conclusões e perspectivas futuras}

Neste trabalho foram relatados e discutidos alguns aspectos relacionados a aplicação de uma sequência didática sobre o uso de elementos da robótica educacional para o ensino das forças de atrito.

No início das atividades sobre atrito os estudantes apresentaram algumas concepções alternativas presentes na literatura da área. Ao final muitos grupos perceberam a diferença entre a força de atrito e o coeficiente de atrito, a dependência dessa força com a normal - que pode ser independente do peso em alguns casos. Alguns grupos explicitaram em suas respostas que essa força tem origem na interação entre as superfícies dos materiais, porém outros ainda apontaram o atrito como uma propriedade dos objetos.

Foram detectados alguns problemas durante as atividades sobre o atrito cinético. O design do experimento permitiu que os estudantes percebessem as flutuações no valor desta força quando o objeto começa a se mover. Entretanto, muitos estudantes associaram essas flutuações a algum tipo de dependência entre o atrito e a área de contato entre as superfícies. Para reduzir esse problema, como apontado por Mossmann et al (2002), foi discutido a origem das flutuações. Contudo, será necessário efetuar modificações na atividade em futuras aplicações, como aumentar a distância percorrida pelo bloco. Cabe ressaltar que, mesmo com os problemas apontados, os estudantes perceberam que o atrito estático diminui quando um objeto começa a se mover.

No início da aplicação da sequência os estudantes pareciam pouco motivados e aparentemente desinteressados. Mas ao final, de maneira geral, gostaram das atividades e da oportunidade de trabalhar em grupo. Eles pareceram interessados para participar de novas atividades e, em menor intensidade, para fazer os relatórios. Este comportamento foi relatado em outros trabalhos (WILLIAMS et al, 2007; MITNIK et al, 2009; TRENTIN et al, 2015).

As respostas dos estudantes durante as atividades permitem afirmar que o uso da robótica educacional em conjunto com questões abertas permite a reflexão sobre os fenômenos, a manifestação das concepções espontâneas, além do movimento para a ressignificação dos conceitos de modo a permitir o aprendizado das concepções cientificamente aceitas na discussão de conceitos da Física diferentes dos utilizados em cinemática.

Para a continuação do trabalho e aprofundamento das investigações será necessário aprimorar as atividades (para a redução dos problemas apontados e permitir mais discussões sobre as concepções espontâneas sobre o atrito apontados na literatura). Para além desse ponto, almeja-se criar novas situações para investigar de forma mais profunda o aprendizado dos estudantes e a importância da robótica educacional no processo de ensino e aprendizagem. Outro aspecto que merece ser investigado é a 
relação entre o uso da robótica educacional e o aumento da motivação para o estudo da Física, algo que atualmente se está pesquisando.

\section{Agradecimentos}

O presente trabalho foi realizado com o apoio da Coordenação de Aperfeiçoamento de Pessoal de Nível Superior - Brasil (CAPES) - Código de Financiamento 001, do Laboratório Interdisciplinar de Formação de Educadores (LIFE - UFSC) e da empresa ATTO Educacional.

\section{Referências}

Aguiar, D. S.; Sampaio, L. I. S.; Sombra, B. P.; Fraga, W. B. (2017) Use of robotics as an alternative methodology for physics teaching. XXII Simpósio Nacional de Ensino de Física. São Carlos: São Paulo

http://www1.sbfisica.org.br/eventos/snef/xxii/sys/resumos/T0749-1.pdf. Accessed in 14 October 2017.

Besson, U.; Borghi, L.; De Ambrosis, A.; Mascheretti, P. (2007) How to teach friction: experiments and models. American Journal of Physics, 75(12), p. $1106-1113$.

Bïlal, E.; Erol, M. (2010) Hypothesis - experiment - instruction (HEI) method for investigation and elimination of misconceptions on friction. Balkan Physics Letters, 18, 181036, p. $269-276$.

Caldas, H.; Saltiel, E. (1995) Le frottment cinetique: Analyse des raisonnements des étudiants. Didaskalia, 6, p. 55 - 71.

Caldas, H. (1999) Atrito. O que diz a Física, o que os alunos pensam e o que os livros explicam. EDUPES, Vitória - ES, Brasil.

Fornazza, R.; Webber, C. G. (2014) Educational robotics applied to physics learning. Revista Novas Tecnologias na Educação, 12(1), 1 - 10.

Hançer, A. H.; Durkan, N. (2008) Turkish Pupils Understanding of Physical Concept: Force and Movement. World Applied Sciences Journal, 3(1), p. 45 - 50.

Mitnik, R.; Recaberren, M.; Nussbaum, M.; Soto, A. (2009) Collaborative robotic instruction: a graph teaching experience. Computers \& Education, 53(2), 330 - 342.

Mossmann, V. L. F.; Catelli, K. B. M. F.; Libardi, H.; Damo, I. S. (2002) Determination of static and kinetic friction coefficients using automatic data collection. Revista Brasileira de Ensino de Física, 24(2), 146 - 149.

Pozo, J. I.; Crespo, M. A. G. (2009) A aprendizagem e o ensino de ciências: do conhecimento cotidiano ao conhecimento científico. $5^{\text {a }}$ ed. Porto Alegre: Artmed.

Rouxinol, E.; Schivani, M.; Andrade, R.; Romero, T. R. L.; Pietrocola, M. (2011) New technologies for physics teaching: a preliminary study of characteristics and activity potential using robotic kits. XIX Simpósio Nacional de Ensino de Física. Manaus: Amazonas.

http://www.nupic.fe.usp.br/Publicacoes/congressos/RESMARRPSNEF2011.pdf.

Accessed in 20 January 2015.

Spolaôr, N.; Benitti, F. B. V. (2017) Robotics applications grounded in learning theories on tertiary education: A systematic review. Computers \& Education, doi: 10.1016/jcompedu.2017.05.001

Trentin, M. A. S.; Rosa, C. T. W.; Rosa, A. B.; Teixeira, A. C. (2015) Free educational robotics in physics teaching: from building the robot to creating a didactical proposal of metacognition orientation. Revista Brasileira de Ensino C\&T, 8(3), 274 - 292.

Williams, D. C.; Ma, Y.; Prejan, L.; Ford, M. J.; Lai, G. (2007) Acquisition of Physics Content Knowledge and Scientific Inquiry Skills in a Robotic Summer Camp. Journal of Research on Technology in Education, 40(2), p. 201 - 216, doi: 10.1080/15391523.2007.10782505 